\title{
Additive Manufacturing: A next gen fabrication
}

\author{
Prajakta Subhedar ${ }^{+*}$ \\ ${ }^{\dagger}$ Mechanical Engineering Department, University of Mumbai, Mumbai, India \\ Received 10 Nov 2017, Accepted 25 Jan 2018, Available online 02 Feb 2018, Vol.8, No.1 (Jan/Feb 2018)
}

\begin{abstract}
A class of technologies referring to Rapid Prototyping (RP) or Additive or Layer Manufacturing or 3D Printing allows designers to quickly create tangible prototype instead of using two dimensional pictures. This technology produces models and prototype parts from 3D CAD model data created from 3D object digitizing systems. Rapid Prototyping forms parts by joining together liquid, powder or sheet materials. Physical models are built using three basic stages: pre-processing, building, post-processing. Pre-processing consists of generation of CAD model, convert into STL format and slice the STL files into cross sectional layers. In building process, construction of model takes place one layer atop another. Post process consists of cleaning and finishing the final model. Common types of Rapid Prototyping technologies popular in industry are: Steriolithography, Fused Deposition Modeling, Selective Laser Sintering, Laminated Object Manufacturing,3 D Printing. The selection of the processes depends upon the material to be cured to build the final model. Rapid Prototyping technologies are used in various industries like Automobiles, Consumer products, Medical, Academics, Aerospace, Government and Military. This poster talks about few challenges to be considered in Rapid Prototyping like shrinkage and distortion of final model, mechanical performance of RP model and limitations to mass quantity.
\end{abstract}

Keywords: Layer Manufacturing, CAD Model, STL format, Steriolithography, Fused Deposition Modeling, Selective Laser Sintering.

\section{Introduction}

AM describes as the technologies that build 3D objects by adding layer upon layer of material, whether the material is plastic, metal, concrete or one day human tissue. It refers to a process by which digital 3D design data is used to build up a component in layers by depositing materials as opposed to subtractive manufacturing methodology, such as traditional machining. The term "3D printing" is increasingly used as synonym for AM, which is clearly distinguished from conventional methods of material removal. For Example, instead of milling a work piece from solid block, AM builds up components layer by layer using materials which are available in either fine powder form or in form of filament. The technology has especially been applied in conjunction with rapid prototyping (Dr. Wei Jun, 2013; The ASTM International Committee F42, 2016)

AM process begins with a3D model of the object, usually created by computer aided design (CAD) software or scan of an existing artifact. Specialized software slices this model into cross-sectional layers, creating a computer file that is sent to the AM machine.
The AM machine then creates the object by adding layers of material on top of each other until the original works are 3D objects.

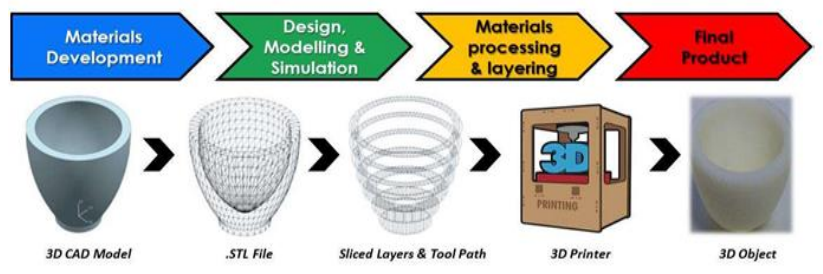

Fig.1 Steps in basic AM process (Dr. Wei Jun, 2013)

The following steps describes a basic AM process (Ian Gibson et al,2010; Moortaz M. Gazhy, 2012):

1) Conceptualization and CAD

2) Converting the CAD model into STL format

3) Transfer to AM machine and STL file manipulation

4) Machine Setup

5) Post processing

There are several systems to classify the AM processes, for e.g. the one proposed by ASTM international 
(American Society for Testing and Materials) classifies the AM processes into 7 areas:(Moortaz M. Gazhy, 2012)

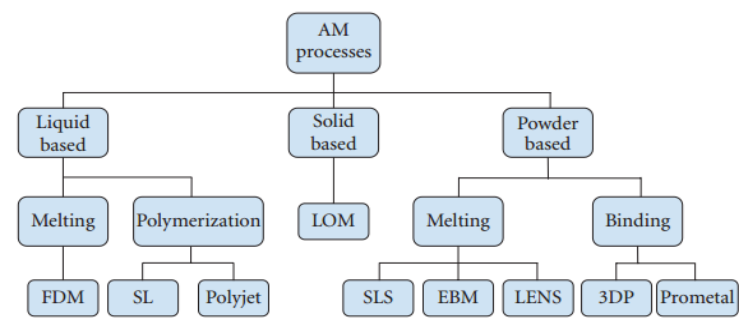

Fig.2 Classification of AM processes

(Advanced Composites Materials and their Manufacture 2 Technology Assessment,2016)

Table 1: Categorizing of various AM processes (Ian Gibson et al,2010; Dr. Wei Jun, 2013)

\begin{tabular}{|c|c|c|}
\hline Process Type & Related Technology & Material Used \\
\hline $\begin{array}{l}\text { Powder bed } \\
\text { fusion }\end{array}$ & $\begin{array}{l}\text { Electron beam melting } \\
\text { (EBM), selective laser } \\
\text { sintering (SLS), selective } \\
\text { heat sintering (SHS), and } \\
\text { direct metal laser } \\
\text { sintering (DMLS) }\end{array}$ & $\begin{array}{l}\text { Metals, } \\
\text { Polymers }\end{array}$ \\
\hline $\begin{array}{l}\text { Directed } \\
\text { Energy } \\
\text { Deposition }\end{array}$ & $\begin{array}{l}\text { Laser metal deposition } \\
\text { (LMD) }\end{array}$ & Metals \\
\hline $\begin{array}{c}\text { Material } \\
\text { Extrusion }\end{array}$ & $\begin{array}{c}\text { Fused deposition } \\
\text { modeling (FDM) }\end{array}$ & Polymers \\
\hline $\begin{array}{c}\text { Vat } \\
\text { Photopolymeri } \\
\text { zation }\end{array}$ & $\begin{array}{c}\text { Stereolithography (SLA), } \\
\text { digital light processing } \\
\text { (DLP) }\end{array}$ & $\begin{array}{c}\text { Photopolymer } \\
\text { S }\end{array}$ \\
\hline Binder Jetting & $\begin{array}{l}\text { Powder bed and inkjet } \\
\text { head (PBIH), plaster- } \\
\text { based 3D printing (PP) }\end{array}$ & $\begin{array}{c}\text { Polymers, } \\
\text { Foundry Sand, } \\
\text { Metals }\end{array}$ \\
\hline $\begin{array}{c}\text { Material } \\
\text { Jetting }\end{array}$ & Multi-jet modeling (MJM) & $\begin{array}{c}\text { Polymers, } \\
\text { Waxes }\end{array}$ \\
\hline $\begin{array}{c}\text { Sheet } \\
\text { Lamination }\end{array}$ & $\begin{array}{c}\text { Laminated object } \\
\text { manufacturing (LOM), } \\
\text { ultrasonic consolidation } \\
\text { (UC) }\end{array}$ & Paper, Metals \\
\hline
\end{tabular}

Selective Laser Sintering (SLS) (Ian Gibson et al,2010; Despa V. et al,2011): The SLS process creates three dimensional objects, layer by layer, from powdered materials with heat generated by a $\mathrm{CO} 2$ laser. The part is built inside of a cylinder that contains a moveable platform, and is formed layer-by-layer. A roller deposits a layer of powder across the top of the cylinder; the laser fuses the powder to create the part geometry and also bonds each layer to the one beneath it; the platform drops by the height of one layer; the roller deposits another layer of powder, and the process continues.

A continuous Laser beams are used or pulsating as heating source for scanning and aligning particles in predetermined sizes and shapes of the layers. The geometry of the scanned layers corresponds to various sections of the models established by computer-aided design (CAD) or from files produced by stereolithography (STL). After scanning the first layer, the scanning continues with the second layer which is placed over the first, repeating the process from the bottom to the top until the product is complete. SLS is known also as solid free and open shape manufacturing process, as a layer fabrication technology, rapid prototyping technology, a selective sintering of metal powders. SLS is reactive when using a chemical reaction of mixing components in the presence of a laser and a selective laser melting (SLM), a direct metal laser sintering (DMLS) or direct metal laser re-melting, when the complete melting of powders is pervasive over the solid state dust sintering. This process was also used in manufacturing moulds, rapid handling of electrodes manufactured, polymer moulds, die casting, die casting of titanium zirconium, bio-medical applications, pieces of zirconium-titanium (PZT) and sheet metal parts.

The SLS process flexibility allows a variety of materials. Some of these materials make the SLS process superior to other rapid prototyping techniques, where the material properties depend on the process. Among these materials, the most common are: wax, paraffin, polymer-metal powders, or various types of steel alloys, polymers, nylon and carbonates. Polycarbonate powders were initially used as starting materials for both experimentation and modelling in the SLS process. For example, a number of systems and metal alloys (Fe-Cu, Fe-Sn, $\mathrm{Cu}-\mathrm{Sn}$ ), metals (Al, $\mathrm{Cr}, \mathrm{Ti}, \mathrm{Fe}$, $\mathrm{Cu})$, ceramics $(\mathrm{Al} 2 \mathrm{O} 3, \mathrm{FeO}, \mathrm{NiO}, \mathrm{ZrO} 2, \mathrm{SiO} 2, \mathrm{CuO})$ and other alloys (bronze, nickel, Inconel 625) were tested for laser sintering. The results demonstrated that any material could be combined with another material with a low melting point and acts as an adhesive.

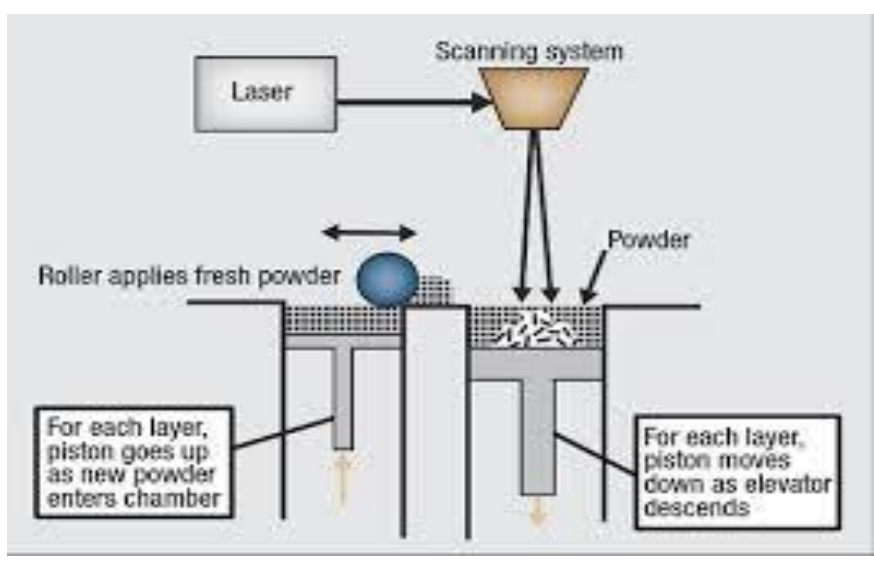

Fig.3 SLS experimental set up (Despa V. et al, 2011)

\section{Advantages of SLS (Rapid prototyping,2016)}

- Fabricated prototypes are porous, thus impairing their strength and surface finish.

- No post curing required.

- $\quad$ Fast build times. 
- Variety of materials.

- Limited use of support structures.

- Enhanced mechanical properties of Nylon and Polycarbonate parts.

\section{Limitations of SLS (Rapid prototyping,2016)}

- Rough surface finish

- Complex operation, many build variables.

- Mechanical properties below those achieved in injection molding for same material.

- Material changeover is difficult compared to FDM and SLA.

- $\quad$ Some post processing/finishing required.

Stereolithography (SLA)(Ian Gibson et al,2010; The ASTM International Committee F42, 2016): Stereolithography can be described as a process capable of producing copies of solid or surface models in plastic materials. The process uses a computer controlled ultraviolet Helium-Cadmium or Argon laser to trace cross-sections of the model onto the surface of a vat of a photocurable polymer, hardening the material. The hardened layer is lowered leaving a new layer of the liquid polymer over the cured material equal in thickness to the slice of the CAD model and the laser traces the next cross-section. This unattended process continues repeatedly until the part is complete.

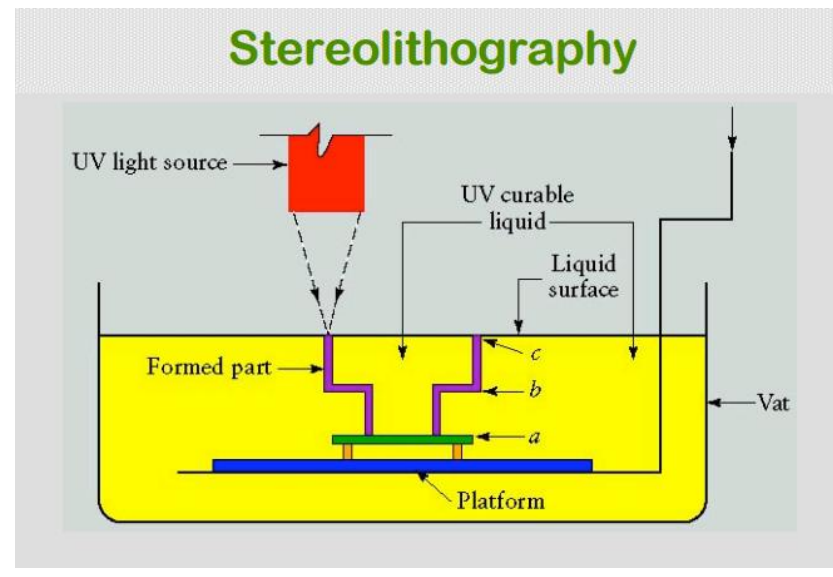

Fig. 4 Stereolithography process (The ASTM International Committee F42, 2016)

The Stereolithography process begins with the conversion of customer 3D CAD Data into an STL file. Proprietary software is used to slice the model into a series of fine layers, with support structures added as necessary. The STL file is then sent to print on the Stereolithography machine. Using a UV laser bream the first cross section of the STL file is traced out onto a platform, placed within the vat of photo-curable resin the resin cures/hardens as it comes into contact with the laser. Once the first layer has been completed the platform is lowered by $0.05-0.15 \mathrm{~mm}$ (dependent on build mode selected) with a fresh layer of resin covering the build surface.
The next layer is then traced out, curing and bonding the resin to the layer below. The stereolithography process repeats layer by layer until the model and any support structures are "fully grown" in the resin. Once complete the platform is raised, allowing excess resin to drain away before the model is removed from the platform.

\section{Advantages of SLA (Rapid prototyping,2016)}

- Achieveing accuracy in industry.

- Capable of high detail and thin walls.

- Market share and industry presence.

- Good surface finish.

\section{Limitations of SLA (Rapid prototyping,2016)}

- $\quad$ Require post curing.

- $\quad$ Limited materials (Photo polymers).

- Shrinkage and curl due to phase change.

- Support structure always needed.

- Removal of support structure can be difficult.

Fused Deposition Modeling (FDM) (Ian Gibson et al,2010; E. Herderick, 2011): As with all 3D printing methods the process begins with the design being created as a CAD file. The data is transferred to the 3D printer where the data is interpreted. The chosen thermoplastic material is placed into the $3 \mathrm{D}$ printer. In a separate location a support material is entered into the $3 \mathrm{D}$ printer. This support material is necessary to hold the object, helping it to retain its form as it dries and grows on the build platform. The object is constructed layer by layer on the 3D printer's build platform. The support material and thermoplastic material are delivered through drive wheels and into two syringe-like tubes and on through dual heated extrusion nozzles. As the two types of material are extruded they are heated by the nozzles. Precise layers of the thermoplastic and support material are squeezed out onto the build platform as the nozzles move across the platform in a horizontal X-Y plane. As each layer is completed the build platform moves down a fraction allowing room for the next layer to be exuded onto the preceding layer.Once the part has been created it is taken from the build platform and the support material which has held the object in place as it was being formed is then removed. The object then has to be cleaned, sanded or polished. There are many finish options which can then be implemented to create smooth even surfaces.

FDM utilizes a thermoplastic filament similar to wire, which is then fed through a heated extruding head controlled by a 3-axis NC-machine. The material hardens immediately when exposed the temperature of the environment. 

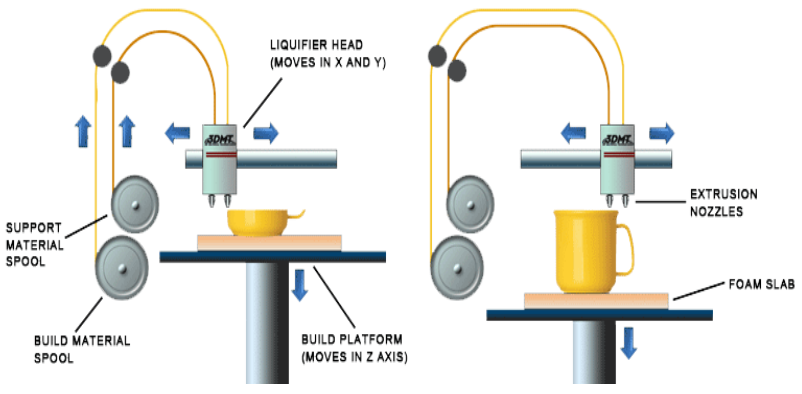

Fig. 9 FEM experimental set up (Ian Gibson et al,2010)

\section{Advantages of FDM (Rapid prototyping,2016)}

- No post curing

- Office environment friendly.

- Variety of materials.

- Low end, economical machines.

- Easy material changeover

\section{Limitations of FDM (Rapid prototyping,2016)}

- Not good for small features, details and thin walls.

- Support design/integration/removal is difficult.

- Surface finish.

- Weak Z axis.

- Supports required for some materials/geometries.

- Slow on large dense parts.

Other AM processes (Ian Gibson et al,2010; The ASTM International Committee F42, 2016)

1) Plaster-based 3D printing (PP)/Ink jet head printing

2) Electron Beam Melting (EBM)

3) Laminated object manufacturing (LOM)

4) Multi jet modeling (MJM)

\section{Applications of Additive Manufacturing}

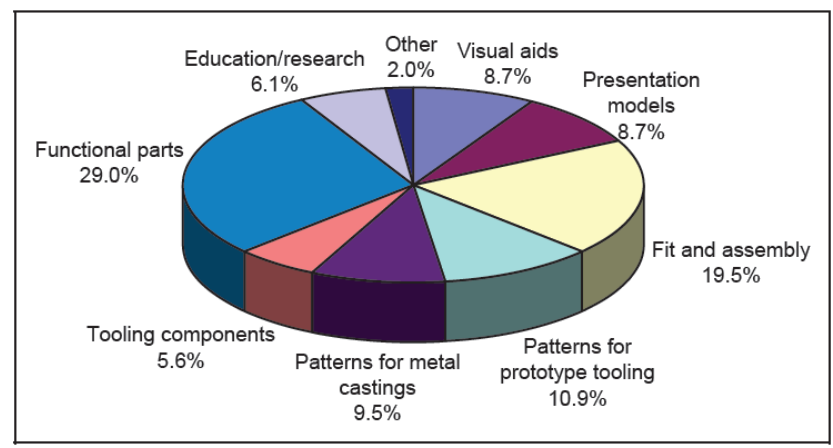

Fig. 13 How consumers use the parts built on AM systems (Kaufui V.Wong et al ,2012)

The next sub-section lists various provides AM applications:

1) Aerospace \& Defense (A\&D) Applications

2) Automotive Applications
3) Electronics Industry Applications

4) Tool and Mold Making Industry

5) Building Sector Applications

6) Biomedical Applications

7) Energy Applications

\section{Conclusions}

- AM processes gives advantages like fast fabrication, versatility of the range of materials, surface finish, accuracy etc.

- But to achieve a wider range of applications for AM, R\&D efforts will need to overcome some key technical challenges are: Process control, Tolerances, Finish, Validation and demonstration, Conventional Manufacturing Bias.

\section{References}

Book by Ian Gibson, David Rosen, Brent stucker 2010, Additive Manufacturing Technologies, $2^{\text {nd }}$ Edition, Springer Publication.

Mootaz M. Gazhy, October 2012, Development of an Additive Manufacturing Decision Support System (AMDSS), School of Mechanical and Systems Engineering Newcastle University, Ph.D thesis.

Dr. Wei Jun, 11 April 2013, Opportunities and Applications of 3D Additive Manufacturing, Singapore Institute of Manufacturing Technology.

Kaufui V.Wong and Aldo Hernandez, Volume 2012, A Review of Additive Manufacturing, ISRN Mechanical Engineering, Article ID 208760, 10 pages doi:10.5402/2012/208760

Despa V., Gheorghe I. Gh., 6, 2011, Study of Selective Laser SinteringA Qualitative and Objective approach, The Scientific Bulletin of Valahia University - Materials and Mechanics.

http://www.acucast.com/rapid_prototyping.html

Ramji Pandey, Photopolymers in 3D printing applications, Arcada University, Degree Thesis, Plastic Technology, I No. 12873.

Ludmila Novakova-Marcincinova, Ivan Kuric, 2012, Basic and Advanced Materials for Fused Deposition Modeling \& Rapid Prototyping Technology, Manuf. and Ind. Eng., 11(1), ISSN 13386549.

E. Herderick, 2011, Additive Manufacturing of Metals: A Review, Materials Science and Technology (MS\&T) 2011, October 16-20, Columbus, Ohio.

Prof. Dr. Ir. J.P. Kruth1, Ir. P. Mercelis1, Prof. Dr. Ir. L. Froyen, Ir. Marleen Rombouts, August 4, 2004, Binding Mechanisms in Selective Laser Sintering and Selective Laser Melting, University of Leuven (K.U. Leuven), Dept. of Metallurgy and Materials Engineering.

The ASTM International Committee F42, 2016, Jan 26, Additive Manufacturing Technologies, retrieved from http:// www.astm.org/ COMMITTEE/F42.htm

Advanced Composites Materials and their Manufacture 2 Technology Assessment (2016, Jan 27), retrieved from http://energy.gov/ sites/prod/files/2015/02/f19/QTR\%20Ch8\%20-\%20Composite $\% 20$ Materials\%20and\%20Manufacture\%20Feb-13-2015.pdf.

Brad Cleveland, July 2009, Prototyping process overview, Advanced materials and processes.

Yu-an Jin, Yong He, Support generation in Additive Manufacturing based on sliced data, International Journal of Advanced Manufacturing technology, springer-verlag, Londaon 2015.

T. Lieneke, G. A. O. Adam, Systematical determination of tolerances for additive manufacturing by measuring linear dimensions, Direct Manufacturing Research Center (DMRC), University of Paderborn, D-33098 Paderborn, Germany.

Brad Cleveland, July 2009 Prototyping process overview, Advanced materials and processes, retrieved from http://www.asminternational.org.

Solution overview (2016, Jan29) retrieved from http://www.3dsystems.com/sites/www.3dsystems.com/files/3D S_CS_Exeter_Uni.pdf

Rapid prototyping (2016 Jan 26), retrieved from http://www.protosystech.com/rapid-prototyping-sla.htm. 